\title{
A SUGGESTION FOR TEACHING THE SPANISH TUTEO
}

Lawrence B. Kiddle

University of Michigan

The problem of how to approach the teaching of the varied Spanish equivalents of our second person address form, you, has disturbed English-speaking students of Spanish and their teachers ever since our language lost the contrast in everyday usage between thou, the intimate and familiar form of address, and you, the polite and respectful form. Centuries ago our linguistic ancestors had in their own language patterns a convenient bridge over which they could pass to an understanding of the Spanish contrast between $t \mathfrak{u}$, intimate and familiar, and usted, polite and respectful. The gulf that separates our contemporary usage from the usted'tu usage in Spanish seems less serious in the case of usted than in the case of $t u$, the stranger of the two forms. As generally happens in other cases where two contrasting forms in Spanish are equivalent to a single English form, e.g.: por, para and ser estar, the stranger and, as here expressed, the second of the two forms tends to be over-used by students. In view of this experience noted by many Spanish teachers the most satisfactory approach to this "two-for-one" type problem would appear to be one based on a careful analysis of the more troublesome or stranger member of the individual contrasting pairs, para, estar, and $t u ́$.

The use of $t \dot{u}$ and its galaxy or set of attendant forms (subject, object and possessive pronouns, finite verb forms, possessive adjectives, etc.), all of which correspond to, a behavior pattern of classifying and modifying speech usgage in contacts with other human beings, is called the tuteo in Spanish. The presentation of this feature to English speakers has been accomplished - or avoided - in a variety of linguistically unsound ways. The purpose of this study is to summarize and criticize the commonly used approaches to the problem of teaching the Spanish tuteo and to offer suggestions for an improved approach. 
My personal experience as a student of Spanish is, perhaps, a convenient way to illustrate certain aspects of the problem under discussion. One of my early teachers had what I am sure she considered a neat solution for the problem of the tuteo. In her instruction she eliminated all the second person forms and stated unequivocally that none of us would ever get to know any Spanish-speaking individual well enough to make use of these forms, so, therefore, we did not need to bother our youthful heads about them. When she further stated that these forms were like our thee and thou, which we only heard when we went to church and only used when we said our prayers or recited poetry, we were convinced of the praiseworthy practicality of her solution. Within the year, however, many of us began to have our doubts about the value of this solution when we struck up friendships with Spanishspeaking fellow students who insisted on using these strange forms we had never learned. Unlike most of my classmates, I went on with my study of Spanish and, for a long time, my fumbling hesitancy in the use of the tuteo forms was, at least in part, due to my early experience with an inadequate presentation of this important feature of Spanish. Continued contacts with Spanish-speaking people in this country and years of residence in Spanish-speaking countries have made it clear to me that we must prepare our students adequately in the use and comprehension of the $t u t e o$.

Not all Spanish teachers have used the Gordian knot tactics of my early teacher, but, judging by the grammars some of them have published, it is possible to say that many of them have violated a basic principle in foreign language teaching that would be familiar to all linguists, namely: that a language must be presented truthfully and completely in normal functional situations. A comparative study of the approach to the tuteo found in a random sampling of twenty grammars used for the teaching of Spanish in American schools and colleges reveals some interesting facts. The grammars referred to are:

1. Agard, Willis and Paratore Speaking and Mriting Spanish (Holt)

2. Barlow basic (Jral Spanzsh (Crofts)

3. Bolinger Intensive Spanish (Russell)

4. Cherubini Curso práctıco del español para princıpı antes (Winston) 
5. De Vitis A Spanısh Grammer tor Beginners (Allyn and Bacon!

6. Hamilton and Van Horne Elementary Spanish Grammar A ppleton-Century)

7. House and Mapes Sharter Spanish Grammar (Ginn)

8. Kany Fractical Spanish (Heath)

9. Keniston Learning Spanish (Holt)

10. La Grone Conversational Spanish Revised (Holt)

11. Leslie Spanzsh for Conversation (Ginn)

12. Levy A Grammar of Everyday Spanish". (Dryden)

13. McSpadden An Introduction to Spanish lisage (Oxford)

14. Ransmeier A Spanısh Recognition Grammar (Chicago)

15. Rogers Spanish for the First Year (Macmillan)

16. Sacks Spanish for Beginners (Ronald)

17. Trevino Spoken Spanzsh (Heath)

18. Turk Foundation Course in Spanish (Heath)

19. Wagner Spanısh Grammar (Wahr)

20. Walsh A Brief Introduction to Spanish(Norton)

The following statements summarize the chief artificial or misleading approache's that appear in the grammars as indicated by the numbers assigned in the previous list:

I. The presentation of the tuteo forms and usage occurs early, i.e. within the first quarter of the text and course, and the forms are a part of the student's memory work yet no natural occurrence or usage situation in the form of dialogue appears until the late lessons, or, in some cases, no such situation ever occurs. Almost without exception these grammars have good dialogue situations where tuteoforms could be used but where a somewhat artificial usted continually appears.

Grammars: $2,4,7,8,11,12,14,15,16,18,19$ 
II. The presentation of the tuteo forms and usage is postponed until after one half or more of the course has been completed.

Grammars: 9,17

III. The tuteo forms are downgraded in importance by being enclosed in parentheses or by being presented in smaller type than the other verb forms or certain $t u t e o$ forms are relegated to an appendix.

Grammars: $3,10,11$

IV. The tuteo forms are translated or equated with thou and re without any explanation of the present-day inadequacy of these equivalents.

Grammars: $\quad 5,11$

V. Spanish American usage is not described. The peninsular Spanish form, vosotros, is not used in Latin America except in sermons. In great areas of Spanish America vos is the intimate form used instead of $t \dot{u}$ Sporadic usage of su merced has been attested in widely separated American regions. While vos and su merred are regionally and socially restricted forms and should not be presented in a grammar except, perhaps, as a footnote, indications as to the absence of vosotros in Spanish American usage should be included.

Grammars: 5,6

VI. Tuteo usage is compared to the French use of $t u$ and the German $d u$ and $2 h r$. This is a risky procedure because a teacher might be trying to explain one unknown by referring to another unknown. ${ }^{1}$ The only grammar that employed this approach was used in a period when it was not uncommon for a Spanish student to have had instruction in French and German prior to studying Spanish. This is rare today.

Grammar: 19

The unfavorable characterizations listed above suggest immediately their opposites or the guiding principles for what

\footnotetext{
1. It is furthermore risky since the usage patterns of French $20 u s$ tu and German : $z e$ au could vary considerably from the Spanish usted $t u$ In other words the similarity could be only superficial.
} 
I consider a realistic and satisfactory approach to presenting the tuteo:

I. Tuteo usage and forms should be presented and used early in keeping with their true frequency of occurrence in the Spanish language. This means not only must the student become acquainted with these forms in the first quarter of his text or course but that he must immediately hear them, read them, and put them to use in their natural situations. On no occasion should the forms be downgraded through typographical or editorial devices.

Grammars with satisfactory presentation: 6, 13,20. 1 is especially praiseworthy.

II. If thou and ye are used as equivalents of $t u ́$ and vosotros the students must be made aware of how inadequate these forms are as translations of the Spanish. For Latin America, however, given the limited occurrence of vosotros, $y e$ is an excellent equivalent at the present time. The use of archaic English forms must be accompanied with historical statements about English usage.

Grammars with satisfactory presentation: 7,9,13. 3 is outstanding.

III. An explanation of Spanish American variations on peninsular Spanish usage should be given, above all in the case of vosotros.

Grammars with satisfactory presentation: $1,8,12$, 13,17. 3 is outstanding.

These three principles, though important, do not include one aspect of the teaching of the tuteo that every foreign language teacher knows is important. I refer to a relatively quick "feeling for" foreign language usage, well expressed in the widely known German term, sprachgefuhl. Once our students have attained this desirable quality our tasks are immeasurably lighter. This, in my opinion, can best be given to our students by comparing the tuteo usage in Spanish with our use of first names in English. Two grammars consulted ( 6 and 13) refer to the similarity of our first name practices and the Spanish tuteo The second of the two grammars actually makes the presence of a first name in a drill sentence an arbitrary indicator that the $t u$ form is required in the 
Spanish translation. These praiseworthy steps are in the right direction and deserve encouragement. The comparative study contained in the remaining paragraphs of this paper seeks to give such encouragement by providing a solid basis for likening tuteo to first-naming. This study is not a linguistic comparison in the narrow sense but rather a cultural comparison.

Based on information obtained in interviews with six informants from Spain (Cjudad Real), Argentina (Buenos Aires), ${ }^{2}$ New Mexico (Taos), Venezuela (Caracas), Colombia (Bogotá), and Perú (Lima), it is possible to establish the norms for $t$ ut eo usage given below. Comparative statements for firstnaming are based on my own experience, i.e. a single informant, a mid-western speaker of English from Cleveland, Ohio.

The tuteo is used as follows:

I. Family Relationships

Affection, closeness of blood ties, filial respect, and openness of character are governing factors in this area. Two distinct pstterns are to be noted: one, corresponding to the traditional Spanish family, in which the children use the usted form in addressing their parents; and the other, representing newer patterns of family relationship, in which the children use the $t u$ form with their parents. In both cases the parents use the $t u^{\prime}$ form with their children. The tradi tional type is found in New Mexico and in Venezuela and the attitude of the informants from these areas toward the innovating type (Spain, Argentina, Colombia, Perú) was in every way comparable to the attitude I would have if I heard a child call his parents by their first names. The presence and growth of the innovating pattern of using the familiar form with one's parents does not offer a parallel to English first-name usage. The traditional type of New Mexico and Venezuela is, however, directly comparable to our firstname practices in the parent-child relationships. Grandparents and grandchildren follow the same pattern of usage as that indicated for parents and children in the areas studied.

2. In the case of Argentinian usage, the widespread use nt the archaic os complicates somewhat this study. All references to Argentinian practice are based on the use of usted vos which I call in this paper tuteo I thus equate it arbitrarily with the usted tu situation in the other areas studied. 
Husbands and wives and sisters and brothers use the tist $e^{\circ}$ just as the first name is used among us. Cousins who are near contemporaries use the tutea. One uses the $t \dot{u}$ form with aunts and uncles as a rule but here the usted form could be used if the person involved were considerably older and reserved in nature. First-naming would be rare in English-speaking famillies in this relationship. The norm is the first name accompanied by aunt and uncle. which would have to be set as a degree between the intimacy of an unaccompanied first name and the formality of a Mr. or Mrs. used with the surname.

\section{School Relationships}

Members of the same school class use the tuteo with each other as we would use the first name. In some areas (Perú, Venezuela, Colombia, New Mexico, Spain) in the elementary grades the teacher is addressed with the $t \dot{u}$ form until the pupils have learned to use the more respectful usted. In Argentina the respectful form, usted. is used by both pupils and teachers throughout the three stages of an educational career: elementary, secondary, and university. For all areas investigated the classroom situation is marked by the usted form of address beyond the elementary level. Exceptions are possible: a teacher may use the $t \dot{u}$ form with students on the secondary and university level if he wishes to express a deeper personal interest in them than what would normally be expected. This change in the norm would be a source of great personal satisfaction to the students involved. They, however, would never use the familiar form in addressing their teachers. In the case of first-naming, English-speaking practices permit the teacher to use the first name at the elementary and secondary level, but not ordinarily at the university level where a more formal student-teacher relationship is maintained. If, at the university level, a teacher did call a student by his first name, it would be a source of great personal satisfaction for the student. In rare cases only would a student at this level address his teacher with his first name. Age difference and openness of character would be governing factors in such a case. 
III Superior-Inferior Relationships

This area in a historical sense is probably the source for the creation of deferential forms of address. Today it is a difficult area to define because of sensitivity to the contrast involved. In some regions of the Spanish-speaking world household servants are addressed with the $t u$ form (Perú) but in other places onlyusted is acceptable to the servants (Venezuela, Argentina, Colombia, Spain), and to use $t \dot{u}$ would mean that the employers were nouveaux riches and unused to having servants. Servants always use the respect forms with employers, usted, mi (la señora, etc. American usage at the present time is hard to define because servants are not so common as they are in Spanishspeaking countries. When I was a boy and when I lived in the South before World War II servants were more common. Then the practice was to call them by their first names. At present formal forms would be used ( $\mathrm{Mr}$. or Mrs. with a surname) with all household employees, who would now work on an hourly basis.

Another situation contained in this category is the officer-subordinate relationship in the military services. In Spain, Colombia, Argentina, and Venezuela officers generally use the usted form with enlisted men although non-commissioned officers occasionaly use the tu form with their subordinates. All enlisted personnel use highly respectful forms with officers $m i$ comandante. $m$, teniente, $m i$ general, etc.l. In Perú officers, whether commissioned or noncomissioned, use the $t u^{\prime}$ form with enlisted men. Our practice is that officers use the title, private. with the surname on formal occasions but generally use the surname alone in addressing a subordinate. The surname in English, contrary to Spanish usage, implies reserve and superiority toward the person addressed. The rapidity with which we pass from the formal $M r$. with a surname to a first name, skipping generally the surname alone, is probably due to this fact.

The last situation to be described is the master-pet relationship. In most Spanish-speaking areas the $t u$ forms would be used with animals. i Luque, échate! ('Duke, lie down!') would be normal in Spain, Perú, Venezuela, New Mexico. However, in Colombia and 
in Argentina 'Duque, échese:', employing the usted form would be usual because, as one informant put it, "there is no real affection felt for an animal." Among us an animal (horse, dog, bird, cat, cow, etc.) would fall into the first-name category in usage.

IV Casual Relationships

In all casual contacts the usted form is used in Spanish unless a great difference in age is present. In such a case the older person addresses the younger with $t$ is but the younger individual will always use the formal form. Incautious use of the $t \hat{u}$ form in these casual relationships suggests the inferior-superior contrast described previously and would produce annoyance and even lead to trouble. Our normal practice would be to use a formal form in casual relationships (sir, mister or $m a(d) a m$ ) and and indiscriminate use of Bud, Mac, Charlie, or Jack, which would be intimate forms for us, would produce a similar annoyance in the person addressed.

V Modification of Relationship

In both Spanish-speaking and English-speaking groups a change in the form of addressing another individual creates a comparable effect. If the change is from formal to intimate, i.e. from using usted to using $t \dot{u}$ or from using $M r ., M r s$. and $M i s s$ with the surname to using the given name, both individuals concerned experience the pleasure of a new relationship. If the change is in the contrary direction, from the intimate address form to the formal form, both individuals ex perience displeasure and unhappiness. In a Spanishspeaking home if a parent addresses his child with usted the child knows that there is trouble ahead. Similarly when my father called me $M r$. Kiddle instead of the usual Lawrence, I was immediately aware that my behavior had been unsatisfactory.

It is probable that cultural comparisons seldom present a perfect one-to-one relationship. This is certainly to be noted in the case of the Spanish tuteo and the English first-name situation. Further research would undoubtedly bring up additional facts about tuteo usage in Spanish-speaking regions but 
it is questionable whether these facts would destroy the general theory concerning the similarity of these two cultural manifestations. The majority of the practices in both areas are in agreement and it is, therefore, possible to tell a student to limit his use of the $t u$ forms to occasions where he would have no hesitancy about using a first name in his own language. 